\title{
DIFERENTES FONTES E NÍVEIS DE LIPÍDEOS NO DESEMPENHO DE LEITÕES PÓS-DESMAME ${ }^{1}$
}

\author{
MARIA EMÍLIA DE SOUSA GOMES PIMENTA ${ }^{2}$ \\ JOSÉ AUGUSTO DE FREITAS LIMA ${ }^{3}$ \\ ELIAS TADEU FIALHO ${ }^{3}$ \\ PRISCILA VIEIRA ROSA LOGATO ${ }^{3}$ \\ LUÍS DA VID SOLIS MURGAS ${ }^{4}$ \\ ANTÔNIO GILBERTO BERTECHINI ${ }^{3}$
}

\begin{abstract}
RESUMO - Utilizaram-se 144 leitões mestiços, sendo 72 machos castrados e 72 fêmeas, com peso médio inicial de $6,91 \mathrm{~kg} \pm 1,32 \mathrm{~kg}$, aos 28 dias de idade, para determinar o efeito da adição ou não de duas fontes de lipídeos (óleo de soja e gordura de coco), em diferentes níveis $(2,4,6$ e 8\%), sobre o desempenho (ganho de peso médio diário, consumo de ração médio diário e conversão alimentar). $\mathrm{O}$ delineamento utilizado foi o DBC, em um arranjo fatorial $2 \times 4$ (fontes x níveis) e um tratamento adicional (ração controle, sem adição de lipídeo). As rações experimentais foram isocalóricas, isoprotéicas e isolisínicas, formuladas à base de milho, farelo de soja, farinha de peixe e leite em pó desnatado, suplementadas com minerais, vitaminas e lisina. Não
\end{abstract}

houve interação significativa entre as fontes e níveis testados $(\mathrm{P}>0,05)$, para nenhum dos parâmetros de desempenho estudados. Não se observou diferença significativa $(\mathrm{P}>0,05)$ no ganho de peso médio diário de leitões que receberam ou não óleo de soja ou gordura de coco, nos diferentes níveis. Comparando-se em conjunto as médias dos tratamentos $(2,4,6,8 \%$ de óleo de soja e de gordura de coco), com a ração-controle (sem adição de lipídeo), foram observados maior $(\mathrm{P}<0,01)$ consumo de ração médio diário e pior $(\mathrm{P}<0,01)$ conversão alimentar, quando não foi adicionado lipídeo à dieta. Pode-se, portanto, concluir que a inclusão de lipídeos às dietas de creche é benéfica, pois proporciona menor consumo de ração, para um mesmo ganho de peso e melhor conversão alimentar.

TERMOS PARA INDEXAÇÃO: Leitões pós-desmame; óleo de soja; gordura de coco; desempenho.

\section{DIFFERENTS SOURCE AND LIPIDS LEVELS IN THE PERFORMANCE OF POS-WEANING PIGLETES}

\begin{abstract}
A total of 144 crossbred piglets were utilized, being 72 castrated males and 72 females, with average initial weight of $6.91 \mathrm{~kg} \pm 1.32 \mathrm{~kg}$, at 28 days old, to determine the effect of the addition or not of two sources of lipids (soybean oil and coconut oil) at different levels $(2,4,6$ and $8 \%$ ) over pigs performance (daily average weight gain, daily average feed intake and feed conversion). It was utilized a randomized block design using a factorial arrangement $2 \times 4$ (sources and oils levels) and an additional treatment (control ration without lipids addition). The experimental rations were isocaloric, isoprotein and isolysine, formulated based on corn, soybean meal, skimmed milk powder fish meal supplemented with
\end{abstract}

minerals, vitamins and lysine. There was no significant interaction between sources and oils levels tested $(\mathrm{P}>0.05)$ for none of the performance parameters studied. Significant difference was not observed $(\mathrm{P}>0.05)$ in the daily average weight gain of pigs receiving or not soybean oil or coconut oil, in different levels. Comparing the means of treatments $(2,4,6,8 \%$ soybean oil and coconut oil) with the control ration (without lipid addition), it was observed larger $(\mathrm{P}<0.01)$ daily average feed intake and worse $(\mathrm{P}<0.01)$ feed conservation when lipid was not added to the diet. The addition of lipids in the piglets diets is beneficial due to smaller ration intake for a same weigh gain and better feed conversion.

\footnotetext{
1. Parte da tese de doutorado em Nutrição de Monogástricos, apresentada ao Departamento de Zootecnia da UFLA - Caixa Postal 37 - 37200-000 - Lavras, MG.

2. Professora da Faculdade de Zootecnia da UNIFENAS.

3. Professores do Departamento de Zootecnia da UFLA.

4. Professor do Departamento de Medicina Veterinária da UFLA.
} 


\section{INTRODUÇÃO}

O uso de gorduras e óleos na alimentação de suínos tem sido um assunto bastante explorado nas últimas décadas; entretanto, o desempenho dos leitões pós-desmame, mediante a utilização de fontes de lipídeos variadas nem sempre tem resultado em melhorias nas taxas de crescimento durante as semanas iniciais pós-desmame e seu uso tem sido, portanto, bastante controverso, conforme pode ser observado nos trabalhos relatados a seguir.

Cera et al. (1989b) adicionaram à ração $8 \%$ de gordura de coco, óleo de milho ou sebo ou $8 \%$ de suas combinações (sebo:gordura de coco, óleo de milho:gordura de coco e sebo:óleo de milho) para leitões machos castrados, desmamados aos 21 dias de idade. Entre as fontes testadas, a adição de gordura de coco aumentou o ganho de peso em todas as semanas e no período experimental total. Na terceira e quarta semanas do experimento e também no período total (durante as quatro semanas), o consumo de ração foi maior para os animais que receberam $8 \%$ de gordura de coco. A conversão alimentar também foi melhor quando a gordura de coco foi adicionada à ração.

Howard et al. (1990), apesar de relatarem um efeito positivo da adição de óleo de soja suplementar em um de seus experimentos, não encontraram nenhum benefício ao realizar novos trabalhos. Esses pesquisadores usaram óleo de soja bruto. É possível, portanto, que o processo de extração do óleo usado no refinamento do óleo de soja melhore seus valores nutricionais nas dietas de leitões pós-desmame. Pelos resultados desses experimentos, infere-se que a resposta do suíno ao óleo de soja degomado e refinado se aproxima da performance de suínos que receberam gordura de coco. Os autores estabelecem que, recebendo uma dieta que contenha qualquer óleo vegetal até um nível de $6 \%$, o crescimento e a eficiência alimentar melhoram no final da fase de creche, comparado com a dieta-controle. O consumo de ração não foi influenciado em nenhum dos dois experimentos.

Mahan (1991) realizou 2 experimentos com leitões mestiços desmamados aos $23 \pm 2$ dias de idade para avaliar o efeito da adição de gordura de coco ou óleo de soja degomado em níveis crescentes $(3,6,9 \%)$. No experimento 1 , as fontes de lipídeo em níveis crescentes foram comparadas a uma dieta-controle (sem adição de lipídeo). Foi demonstrado que nem a gordura de coco, nem o óleo de soja influenciaram no ganho de peso diário, consumo de ração ou conversão alimentar durante os primeiros 14 dias pós-desmame, quando comparado com a dieta-controle. Dos 15 aos 35 dias pós-desmame, houve uma melhoria no ganho de peso e eficiência alimentar, com o aumento do nível de lipídeo na dieta, mas não foi observado nenhum efeito sobre o consumo de ração. No período total, o ganho de peso e a eficiência alimentar aumentaram com o aumento do nível de lipídeo na dieta.

Embora a resposta de ganho dos 15 aos 35 dias e por todo o período experimental tenham sido linearmente significativas, os dados encerram um platô, sem resposta de crescimento acima de $6 \%$ de adição de qualquer fonte de lipídeo (MAHAN, 1991). A eficiência alimentar melhorou linearmente, tanto de 15 a 35 dias quanto no período experimental total, quando o nível de qualquer uma das fontes aumentou. No experimento 2, Mahan (1991) avaliou o efeito de 2 dietas contendo produtos lácteos, sem adição de lipídeo, durante os primeiros 14 dias pós-desmame e o efeito do fornecimento de $6 \%$ de lipídeo suplementar (gordura de coco, óleo de soja ou a combinação dos 2) subseqüentemente a essas 2 semanas iniciais, nos próximos 21 dias. Durante os 14 dias iniciais, os animais que receberam a dieta com alta densidade de nutrientes apresentaram os mais altos ganhos de peso e consumo de ração, comparados com os animais que consumiram dieta-controle. Embora tenha havido um pequeno benefício da dieta com alta densidade de nutrientes na eficiência alimentar, a resposta não foi significativa. Dos 15 aos 35 dias pós-desmame houve uma pequena vantagem no ganho de peso dos leitões que receberam dietas contendo gordura de coco. Entretanto, o ganho de peso com o fornecimento de qualquer uma das fontes de lipídeos foi superior à ração basal (sem adição de lipídeo). O consumo de ração durante os 21 dias finais foi semelhante para todos os tratamentos. Com relação à conversão alimentar, essa foi semelhante quando se usou gordura de coco ou óleo de soja. Os suínos que receberam gordura de coco ou óleo de soja ou a combinação dos dois tiveram mais altas taxas de crescimento e melhor conversão alimentar que os que consumiram a ração basal durante o período dos 15 aos 35 dias pós-desmame.

De acordo com Mahan (1991), a resposta superior da gordura de coco é atribuída ao seu menor comprimento de cadeia e a sua mais alta taxa de absorção via corrente sanguínea, comparada com os ácidos graxos de outros lipídeos vegetais e animais, os quais são mais rapidamente absorvidos via sistema linfático. Os óleos vegetais, entretanto, contêm uma alta proporção de ácidos graxos insaturados, em relação aos saturados 
e uma digestibilidade aparente mais alta que as fontes lipídicas de origem animal (SEWELL e MILLER, 1965; CERA et al., 1988, 1989a). Conseqüentemente, os óleos vegetais são, comumente, mais benéficos nas dietas iniciais que as gorduras de origem animal.

Dove (1993), em seus estudos, forneceu dieta basal (sem adição de lipídeo), 5\% de um triacilglicerol de cadeia média (da mesma família da gordura de coco), $5 \%$ do óleo de soja e 5\% de gordura animal. Esse autor observou que a adição de triacilglicerol de cadeia média aumentou o ganho de peso nas duas primeiras semanas pós-desmame, comparado às outras fontes. Esses resultados são opostos aos encontrados por Cera et al. (1990a), em que os leitões que receberam essa fonte lipídica diminuíram o consumo e a taxa de crescimento. Esse fato pode ser explicado pela diferença na composição dos ácidos graxos do triacilglicerol. Segundo Dove (1993), outros fatores, incluindo composição da dieta, idade dos suínos, ambiente da creche e manejo, também podem influenciar nas respostas ao triacilglicerol de cadeia média de cada experimento. O óleo de soja e a gordura animal não afetaram o ganho de peso durante os primeiros 14 dias de experimento.

Jin et al. (1998) avaliaram o efeito da adição de gordura de coco, óleo de milho, óleo de soja, sebo e sebo+lecitina no desempenho e utilização de nutrientes para suínos desmamados aos 21 dias de idade (pesando, em média, 5,8 kg). De 0 a 7 dias pós-desmame, os animais que receberam lipídeos de origem vegetal obtiveram maior ganho de peso diário e melhor conversão alimentar. $\mathrm{O}$ consumo de ração foi semelhante entre os tratamentos. De 8 a 14 dias pós-desmame, os leitões que receberam gordura de coco ou óleo de soja tiveram melhor ganho de peso diário e melhor consumo de ração que os outros tratamentos. De 15 a 21 dias, os animais que receberam o sebo tiveram menores ganhos que os que receberam óleos de origem vegetal ou sebo + lecitina. A gordura de coco foi mais efetiva em melhorar o crescimento de suínos durante as 2 primeiras semanas pós-desmame e o óleo de milho e o óleo de soja tiveram valores igualmente inferiores na melhoria do desempenho de suínos desmamados.

Jones et al. (1992) realizaram um experimento com leitões desmamados aos 21 dias de idade. Foram usados $10 \%$ de óleo de soja, $10 \%$ de sebo e dietacontrole (sem adição de lipídeo). Não houve diferença de conversão alimentar entre as fontes, mas os animais que receberam a dieta-controle apresentaram pior conversão alimentar.
Em razão dos resultados controversos de vários experimentos, torna-se necessário avaliar o desempenho de leitões desmamados, recebendo diferentes níveis de lipídeos adicionados às rações.

Entretanto, deve-se considerar que o desempenho dos leitões do nascimento às nove semanas de idade não só apresenta implicações financeiras importantes, como também é crítico na determinação de correlações entre peso e idade subseqüentes e, possivelmente, do percentual de carne magra da carcaça.

Diante dessa realidade, objetivou-se com o presente experimento avaliar o desempenho (ganho de peso médio diário, consumo de ração médio diário e conversão alimentar) de leitões na fase de creche (dos 28 aos 63 dias de idade), ao receberem ou não óleo de soja ou gordura de coco em níveis crescentes $(2,0 ; 4,0 ; 6,0$ ou $8,0 \%)$.

\section{MATERIAL E MÉTODOS}

O experimento foi conduzido de 26 de outubro de 2000 a 9 de fevereiro de 2001, na creche do Setor de Suinocultura do Departamento de Zootecnia da Universidade Federal de Lavras (UFLA).

Foram utilizados 144 leitões mestiços (Landrace $\mathrm{x}$ Largewhite), provenientes do próprio Setor de Suinocultura, sendo 72 machos castrados e 72 fêmeas. O peso inicial dos animais foi $6,91 \mathrm{~kg} \pm 1,32 \mathrm{~kg}$ (aos 28 dias de idade), e os mesmos foram desmamados aos 21 dias \pm 4 dias. O peso final foi $23,32 \mathrm{~kg} \pm 2,00 \mathrm{~kg}$, quando os animais atingiram a idade de 63 dias \pm 4 dias.

Esses foram alojados em baias suspensas de alvenaria contendo bebedouro tipo chupeta e comedouro semi-automático. Para evitar oscilações bruscas de temperatura, foram acionadas lâmpadas à noite, durante toda a madrugada e até às 6 horas da manhã, nas duas primeiras semanas pós-desmame.

Em cada baia foram colocados 2 machos castrados e 2 fêmeas.

O período pré-experimental teve a duração de 7 dias (dos 21 aos 28 dias de idade), durante o qual se observaram os animais que apresentavam problemas, a fim de eliminá-los antes do início do experimento. Durante esse período, os animais receberam o tratamento que seria destinado a eles, durante todo o período experimental.

Foram avaliadas 2 fontes de lipídeos (óleo de soja e gordura de coco) em diferentes níveis $(2,4,6$ e $8 \%$, comparadas à ração basal (sem adição de lipídeo). Portanto, o delineamento experimental utilizado foi o de blocos casualizados, sendo os blocos no tempo formados 
por não haver espaço físico e animais suficientes para iniciar de uma só vez o trabalho de campo. Os tratamentos foram arranjados em um esquema fatorial $2 \times 4$ (fontes $\mathrm{x}$ níveis), além de um tratamento adicional (ração basal).

As rações experimentais foram produzidas na Fábrica de Ração do Departamento de Zootecnia da Universidade Federal de Lavras e a composição química dos ingredientes usados encontra-se na Tabela 2.

As rações foram fareladas, isocalóricas, isoprotéicas e isolisínicas e formuladas à base de milho, farelo de soja, leite em pó desnatado, farinha de peixe, além das fontes de lipídeos (óleo de soja e gordura de coco), nos diferentes níveis. Foram também suplementadas com minerais, vitaminas, lisina e metionina, para atender às recomendações do NRC (1998), conforme Tabelas 3 e 4. Para prevenir a oxidação lipídica, adicionou-se etoxiquim. As rações e a água foram fornecidas ad libitum.

Para avaliação do desempenho, foram utilizados todos os 144 leitões; portanto, foram formados 4 blocos, que receberam durante 35 dias (período experimental) as rações apresentadas nas Tabelas 3 e 4 . A baia, contendo 2 machos e 2 fêmeas, constituiu a unidade experimental.

$\mathrm{O}$ peso dos animais e o consumo de ração foram controlados a cada 7 dias.

As variáveis estudadas foram: ganho de peso médio diário, consumo de ração médio diário e conversão alimentar.

O modelo estátistico utilizado foi: $\mathrm{Y}_{(\mathrm{ijk})}=\mathrm{M}+\mathrm{b}_{(\mathrm{i})}+\mathrm{f}_{(\mathrm{j})}+\mathrm{n}_{(\mathrm{k})}+\mathrm{fn}_{(\mathrm{jk})}+\mathrm{e}_{(\mathrm{ijk})}$, em que: $\mathrm{i}=1,2,3,4$ (número de blocos) $\mathrm{j}=1,2$ (número de fontes)

$\mathrm{k}=1,2,3,4$ (número de níveis)

Para analisar o tratamento adicional (raçãocontrole, sem adição de lipídeo) versus fatorial, o modelo estatístico foi o seguinte:

$\mathrm{Y}_{\mathrm{ij}}=\mathrm{M}+\mathrm{b}_{\mathrm{i}}+\mathrm{T}_{\mathrm{j}}+\mathrm{e}_{\mathrm{ij}}$

$\mathrm{i}=1,2,3,4$ (número de blocos)

$\mathrm{j}=1,2$ (número de tratamentos)

Todas as análises foram realizadas utilizando-se o pacote computacional SISVAR.

\section{RESULTADOS E DISCUSSÃO}

Os resultados de ganho de peso médio diário, consumo de ração médio diário e conversão alimentar, para leitões recebendo diferentes fontes e níveis de lipídeo na dieta, durante o período experimental total, encontram-se na Tabela 4.

Por meio desses resultados constata-se que não foram observadas diferenças significativas $(P>0,05)$ no ganho de peso médio diário de leitões alimentados ou não com rações contendo óleo de soja ou gordura de coco, nos diferentes níveis testados. Entretanto, comparando-se em conjunto as médias dos tratamentos $(2,4$, $6,8 \%$ de óleo de soja e de gordura de coco) com a ração controle (sem adição de lipídeo), foi observado maior consumo de ração médio diário $(\mathrm{P}<0,01)$ e pior conversão alimentar $(\mathrm{P}<0,01)$ para os leitões alimentados com rações sem adição de lipídeo; resultados similares foram também obtidos por Mahan (1991).

TABELA 1 - Proteína Bruta (PB), Energia Digestível (ED), Cálcio (Ca), Fósforo Disponível (PD), Lisina (Lis) e Metionina + Cistina (Met + Cis) dos ingredientes utilizados nas rações experimentais.

\begin{tabular}{lcccccc}
\hline \multicolumn{1}{c}{ Ingredientes } & $\begin{array}{c}\text { PB } \\
(\boldsymbol{\%})^{\mathbf{1}}\end{array}$ & $\begin{array}{c}\text { ED } \\
(\mathbf{k c a l} / \mathbf{k g})^{\mathbf{2}}\end{array}$ & $\begin{array}{c}\text { Ca } \\
(\boldsymbol{\%})^{\mathbf{1}}\end{array}$ & $\begin{array}{c}\text { P } \\
(\boldsymbol{\%})^{\mathbf{1}}\end{array}$ & $\begin{array}{c}\text { Lis } \\
(\mathbf{\%})^{\mathbf{2}}\end{array}$ & $\begin{array}{c}\text { Met + Cis } \\
(\boldsymbol{\%})^{\mathbf{2}}\end{array}$ \\
\hline Milho & 8,90 & 3476 & 0,03 & 0,25 & 0,25 & 0,40 \\
Farelo de soja & 45,20 & 34,21 & 0,36 & 0,55 & 2,78 & 1,27 \\
Farinha de peixe & 60,00 & 3103 & 6,10 & 3,36 & 4,24 & 2,56 \\
Leite em pó desnatado & 33,60 & 3816 & 1,19 & 0,94 & 2,71 & $-1,27$ \\
Amido de milho & 0,55 & 3708 & - & - & - & - \\
Óleo de soja & - & 8469 & - & - & - & - \\
Gordura de coco & - & 8565 & - & - & -
\end{tabular}

${ }^{1}$ Valores segundo análises realizadas no Laboratório de Análise de Alimentos - ICA - Universidade de Alfenas (UNIFENAS), expressos na matéria natural.

${ }^{2}$ Rostagno et al. (2000).

Ciênc. agrotec., Lavras. V.27, n.5, p.1130-1137, set./out., 2003 
TABELA 2 - Rações experimentais contendo óleo de soja em diferentes níveis, para leitões na fase de creche.

\begin{tabular}{|c|c|c|c|c|c|}
\hline \multirow{2}{*}{ Ingrediente } & \multirow{2}{*}{ Basal } & \multicolumn{4}{|c|}{ Nível de Óleo de Soja (\%) } \\
\hline & & 2 & 4 & 6 & 8 \\
\hline Milho & 59,60 & 61,90 & 56,40 & 50,30 & 44,40 \\
\hline F. Soja & 22,00 & 21,5 & 22,50 & 23,60 & 24,70 \\
\hline Leite desn. em pó & 5,00 & 5,00 & 5,00 & 5,00 & 5,00 \\
\hline F. Peixe & 4,00 & 4,00 & 4,00 & 4,00 & 4,00 \\
\hline Amido & 6,00 & 0,00 & 0,00 & 0,00 & 0,00 \\
\hline $\mathrm{Lis}-\mathrm{HCl}$ & 0,20 & 0,20 & 0,20 & 0,20 & 0,20 \\
\hline Metionina & 0,12 & 0,12 & 0,12 & 0,12 & 0,12 \\
\hline Calcário & 0.90 & 0,90 & 0,90 & 0,90 & 0,90 \\
\hline Fosf. bicálc. & 0,70 & 0,70 & 0,70 & 0,70 & 0,70 \\
\hline Sal & 0,40 & 0,40 & 0,40 & 0,40 & 0,40 \\
\hline Premix $^{1}$ & 0,25 & 0,25 & 0,25 & 0,25 & 0,25 \\
\hline Óleo de soja & 0,00 & 2,00 & 4,00 & 6,00 & 8,00 \\
\hline Etoxiquim & 0.05 & 0,05 & 0,05 & 0,05 & 0,05 \\
\hline Caulim & 0.78 & 2,98 & 5,48 & 8,48 & 11,28 \\
\hline TOTAL & 100,00 & 100,00 & 100,0 & 100,00 & 100,00 \\
\hline \multicolumn{6}{|l|}{ Valores calculados ${ }^{2}$ : } \\
\hline $\mathrm{PB}(\%)$ & 19,30 & 19,30 & 19,30 & 19,20 & 19,20 \\
\hline ED (Kcal/kg) & 3362 & 3371 & 3384 & 3378 & 3380 \\
\hline $\mathrm{Ca}(\%)$ & 0,92 & 0,92 & 0,92 & 0,91 & 0,92 \\
\hline $\mathrm{P}(\%)$ & 0,58 & 0,58 & 0,57 & 0,55 & 0,56 \\
\hline Lis $(\%)$ & 1,26 & 1,26 & 1,27 & 1,28 & 1,30 \\
\hline
\end{tabular}

${ }^{1}$ Minerais: Fe, 90g; Cu, 10g; Co, 2g; Mn, 40g; Zn, 70g; I, 2g; Excipiente q.s.p.500g / Vitaminas: Vit.A, 10.000.000 U.I.; Vit. D. 1.000.000 U.I.; Vit.E, 15.000 U.I.; Vit.B 1 , 3g; Vit.B2, 3g; Vit.B 6 , 1,5g; Ácido Pantotênico, 12g; Vit.C, 30g; Vit.K 3 , 2,5g; Ácido Nicotínico, 22g; Vit.B 12 , 22mg; Ácido Fólico, 0,6g; Biotina, 0,1g; Antioxidante, 30g; Excipiente q.s.p. 2000g.

${ }^{2}$ Com base na Tabela 1.

Ciênc. agrotec., Lavras. V.27, n.5, p.1130-1137, set./out., 2003 
TABELA 3 - Rações experimentais contendo gordura de coco em diferentes níveis, para leitões na fase de creche.

\begin{tabular}{|c|c|c|c|c|c|}
\hline \multirow{2}{*}{ Ingrediente } & \multirow{2}{*}{ Basal } & \multicolumn{4}{|c|}{ Nível de Gordura de Coco (\%) } \\
\hline & & 2 & 4 & 6 & 8 \\
\hline Milho & 59,60 & 61,90 & 56,10 & 49,80 & 44,00 \\
\hline F. Soja & 22,00 & 21,50 & 22,50 & 23,80 & 24,80 \\
\hline Leite desn. Em Pó & 5,00 & 5,00 & 5,00 & 5,00 & 5,00 \\
\hline F. Peixe & 4,00 & 4,00 & 4,00 & 4,00 & 4,00 \\
\hline Amido & 6,00 & 0,00 & 0,00 & 0,00 & 0,00 \\
\hline $\mathrm{Lis}-\mathrm{HCl}$ & 0,20 & 0,20 & 0,20 & 0,20 & 0,20 \\
\hline Metionina & 0,12 & 0,12 & 0,12 & 0,12 & 0,12 \\
\hline Calcário & 0,90 & 0,90 & 0,90 & 0,90 & 0,90 \\
\hline Fosf. Bicálc. & 0,70 & 0,70 & 0,70 & 0,70 & 0,70 \\
\hline Sal & 0,40 & 0,40 & 0,40 & 0,40 & 0,40 \\
\hline Premix $^{1}$ & 0,25 & 0,25 & 0,25 & 0,25 & 0,25 \\
\hline Gordura de Coco & 0,00 & 2,00 & 4,00 & 6,00 & 8,0 \\
\hline Etoxiquim & 0,05 & 0,05 & 0,05 & 0,05 & 0,05 \\
\hline Caulim & 0,78 & 2,98 & 5,78 & 8,78 & 11,58 \\
\hline TOTAL & 100,00 & 100,00 & 100,00 & 100,00 & 100,00 \\
\hline \multicolumn{6}{|l|}{ Valores calculados ${ }^{2}:$} \\
\hline $\mathrm{PB}(\%)$ & 19,30 & 19,30 & 19,30 & 19,30 & 19,20 \\
\hline $\mathrm{ED}(\mathrm{Kcal} / \mathrm{kg})$ & 3362 & 3373 & 3378 & 3374 & 3377 \\
\hline $\mathrm{Ca}(\%)$ & 0,92 & 0,92 & 0,92 & 0,91 & 0,92 \\
\hline $\mathrm{P}(\%)$ & 0,58 & 0,58 & 0,57 & 0,56 & 0,56 \\
\hline Lis $(\%)$ & 1,26 & 1,26 & 1,26 & 1,28 & 1,30 \\
\hline
\end{tabular}

${ }^{1}$ - Minerais: Fe, 90g; Cu, 10g; Co, 2g; Mn, 40g; Zn, 70g; I, 2g; Excipiente q.s.p.500g / Vitaminas: Vit.A,

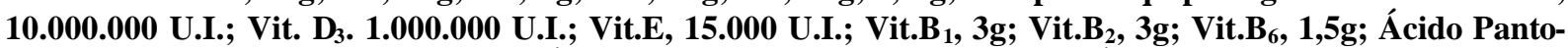
tênico, 12g; Vit.C, 30g; Vit.K $\mathrm{K}_{3}, 2,5 \mathrm{~g}$; Ácido Nicotínico, 22g; Vit.B 12 , 22mg; Ácido Fólico, 0,6g; Biotina, 0,1g; Antioxidante, 30g; Excipiente q.s.p. 2000g.

2 - Com base na Tabela 1.

Ciênc. agrotec., Lavras. V.27, n.5, p.1130-1137, set./out., 2003 
TABELA 4 - Ganho de Peso Médio Diário (GPMD), Consumo de Ração Médio Diário (CRMD) e Conversão Alimentar (CA) de leitões aos 63 dias de idade, de acordo com as fontes e níveis de lipídeos fornecidos na dieta.

\begin{tabular}{ccccc}
\hline \multirow{2}{*}{ Fonte } & Níveis $(\%)$ & GPMD & $\begin{array}{c}\text { CRMD } \\
\text { (kg/dia) }\end{array}$ & CA \\
\cline { 3 - 5 } & & 0,450 & 0,742 & 1,65 \\
& 2 & 0,454 & 0,666 & 1,47 \\
Óleo de Soja & 4 & 0,503 & 0,716 & 1,42 \\
& 6 & 0,470 & 0,631 & 1,34 \\
& 8 & 0,469 & 0,689 & 1,47 \\
\hline \multirow{2}{*}{ Gordura de Coco } & Média & 0,464 & 0,758 & 1,63 \\
& 2 & 0,404 & 0,661 & 1,64 \\
& 4 & 0,445 & 0,700 & 1,57 \\
& 6 & 0,486 & 0,781 & 1,61 \\
& & 0,450 & 0,725 & 1,61 \\
\hline Controle (sem adição de lipídeo) & & 0,421 & $0,851^{\mathrm{a}}$ & $2,02^{\mathrm{a}}$ \\
\hline & & 13,01 & 9,68 & 19,21 \\
\hline
\end{tabular}

\section{${ }^{\text {a }}$ Contraste controle vs fatorial $(\mathbf{P}<0,01)$.}

Considerando-se ainda que as rações foram isoenergéticas (Tabelas 2 e 3) e observando-se os consumos médios diários em cada tratamento, nota-se claramente que ocorreu uma diminuição da consumo diário de energia digestível, à medida que se incorporou lipídeo às dietas, independente da fonte testada.

Portanto, pode-se inferir que, durante o período experimental total (35 dias), o fornecimento de qualquer uma das fontes de lipídeo na dieta propiciou uma economia média de $20,3 \%$ de ração, proporcionando ganho de peso semelhante.

Os trabalhos sobre desempenho de leitões que receberam as fontes testadas têm sido controversos e a maioria deles aponta vantagens para a utilização da gordura de coco (CERA et al., 1989a; Jin et al., 1998), devido ao seu comprimento de cadeia característico (cadeia média) e à sua mais alta taxa de absorção, uma vez que não necessitam da assistência de uma micela para a sua absorção pela mucosa intestinal e por não serem convertidos aos seus derivados CoA, sendo liberados direto na circulação portal, onde são transportados pela albumina sérica até o fígado (CHAMPE e HARVEY, 1996). Entretanto, alguns autores têm verificado respostas de crescimento durante o final do período de creche, quando outros óleos vegetais são fornecidos (CERA et al., 1989a, 1990b; HOWARD et al., 1990), inclusive o óleo de soja. No presente experimento, o óleo de soja utilizado foi o refinado pois, segundo Howard et al. (1990), é possível que o processo de extração de óleo melhore seus valores nutricionais. Esses autores inclusive ressaltam que o desempenho de leitões recebendo óleo de soja degomado e refinado, se aproxima do desempenho dos animais recebendo gordura de coco.

\section{CONCLUSÕES}

Considerando o desempenho dos leitões que receberam os diferentes tratamentos, observou-se que a inclusão de lipídeo às dietas de creche é benéfica, pois proporciona menor consumo de ração para um mesmo ganho de peso, promovendo, portanto, melhor conversão alimentar. Conclui-se assim que a utilização de $2 \%$ 
de inclusão da fonte de lipídeo que for de menor custo em rações de leitões dos 6,9 aos $23 \mathrm{~kg}$ é tecnicamente a mais adequada.

\section{REFERÊNCIAS BIBLIOGRÁFICAS}

CERA, K. R.; MAHAN, D. C.; REINHART, G. A. Weekly digestibilities of diets supplemented with corn oil, lard or tallow by weanling swine. Journal of Animal Science, Champaign, v. 66, n. 6, p. 14301438, June 1988.

CERA, K. R.; MAHAN, D. C.; REINHART, G. A. Apparent fat digestibilities and performance responses of postweaning swine fed diets supplemented with coconut oil, corn oil or tallow. Journal of Animal Science, Champaign, v. 67, n. 8, p. 2040-2047, Aug. 1989a.

CERA, K. R.; MAHAN, D. C.; REINHART, G. A. Postweaning swine performance and serum profile responses to supplemental medium-chain free fatty acids and tallow. Journal of Animal Science, Champaign, v. 67, n. 8, p. 2048-2055, Aug. 1989b.

CERA, K. R.; MAHAN, D. C.; REINHART, G. A. Effect of weaning, week postweaning and diet composition on pancreatic and small intestinal luminal lipase response in young swine. Journal of Animal Science, Champaign, v. 68, n. 2, p. 384- 390, Feb. 1990a.

CERA, K. R.; MAHAN, D. C.; REINHART, G. A. Evaluation of various extrated vegetable oils, roasted soybeans, medium-chain triglyceride and na animalvegetable fat blend for postweaning swine. Journal of Animal Science, Champaign, v. 68, n. 9, p. 2756 2765, Sept. $1990 b$

CHAMPE, P. C.; HARVEY, R. A. Bioquímica ilustrada. 2. ed. Porto Alegre: Artes Médicas, 1996. 446 p.

DOVE, C. R. The effect of adding copper and various fat sources to the diets of weanling swine on growth- performance and serum fatty-acid profiles. Journal of Animal Science, Champaign, v. 71, n. 8, p. 21872192, Aug. 1993.

HOWARD, K. A.; FORSYTH, D. M.; CLINE, T. R. The effect of na adaption period to soybean oil additions in the diets of young pigs. Journal of Animal Science, Champaign, v. 68, n. 3, p. 678-688, Mar. 1990.

JIN, C. F.; KIM, J. H.; HAN, I. K.; JUNG, H. J.; KWON, C. H. Effects of various fat sources and lecithin on the growth performance and nutrient utilization in pigs weaned at 21 days of age. Asian-australasian Journal of Animal Sciences, Suweon, v. 11, n. 2, p. 176-184, Apr. 1998.

JONES, D. B.; HANCOCK, J. D.; HARMON, D. L.; WALKER, C. E. Effects of exogenous emulsifiers and fat sources on nutrient digestibility, serum-lipids, and growth-performance in weanling pigs. Journal of Animal Science, Champaign, v. 70, n. 11, p. 34733482, Nov. 1992.

MAHAN, D. C. Efficacy of initial postweaning diet and supplemental coconut oil or soybean oil for weanling swine. Journal of Animal Science, Champaign, v. 69, n. 4, p. 1397-1402, Apr. 1991.

NATIONAL RESEARCH COUNCIL. Nutrient requirement of swine. $10^{\text {th }}$. rev. ed. Washington: National Academy, 1998. 58 p.

ROSTAGNO, H. S.; ALBINO, L. F. T.; DONZELE, J. L.; GOMES, P. C.; FERREIRA, A. S.; OLIVEIRA, R. F.; LOPES, D. C. Tabelas brasileiras para aves e suínos: composição de alimentos e exigências nutricionais. Viçosa: UFV, 2000. 141 p.

SEWELL, R. F.; MILLER, I. L. Utilization of various dietary fats by baby pigs. Journal of Animal Science, Champaign, v. 24, n. 4, p. 973-980, Nov. 1965. 